\title{
A TRADUÇÃO NO NINAR DE UMA CANTIGA: ENTRE O RITMO, O SENTIDO E A ALTERIDADE
}

\author{
Rosanne Castelo Branco ${ }^{1}$
}

\begin{abstract}
RESUMO
O presente artigo objetiva discutir abordagens entre a narrativa oral, ritmo e tradução no contexto do gênero da cantiga de ninar infantil francesa "Frère Jacques", observando as variáveis fônicas e de sentido, originadas do contraponto léxico-semântico-cultural resultante da tradução da produção oral francesa,como língua de partida,tanto quanto para a língua alemã e para a língua inglesa, como línguas de chegada. A investigação visa analisar, mais particularmente, de como se dá o fenômeno da tradução na inter-relação da poética com essas instâncias oriundas de tradução, considerando suas vozes, ritmo, humor e performances, buscando apontar as estratégias utilizadas pela tradução,de forma a manter a musicalidade e manutenção da obra na sua completude poética. Para fundamentar e dar sustentabilidade a essa investigação, no âmbito da Poética, da Oralidade e da Tradução foram considerados os pensamentos de teóricos como Paul Zumthor (1993), Henri Meschonnic (2010), Antoine Berman (2013), Georges Mounin (1963) e Octavio Paz (1991) . Durante as abordagens e análises poderemos constatar que na oralidade da cantiga de ninar, assegurar a musicalidade fonética e o ritmo têm mais relevância do que o caráter lexical e semântico.
\end{abstract}

Palavras-chaves: Oralidade. Cantiga de Ninar. Tradução poética. Alteridade

\begin{abstract}
This article aims to discuss approaches between the oral narrative, rhythm and translation in the gender context of French children's lullaby "Frère Jacques," noting the phonic and direction variables, originating from lexical-semantic-cultural counterpoint resulting from translation of French oral production as the source language, as well as for the German language and the English language as target languages. The research aims to analyze, more particularly, how it is the phenomenon of translation in the interrelation of poetics with these instances arising from translation, considering their voices, rhythm, mood and performances, seeking to identify the strategies pursued by the translation in order to maintain musicality and maintenance of the work in its poetic completeness. To support and give sustainability to this investigation, within the Poetics, Orality and Translation, were considered the thoughts of theorethical as Paul Zumthor(1993), Henri Meschonnic(2010), Antoine Berman (2013), Georges Mounin (1963) and Octavio Paz (1991) . During the approaches and analysis, we can see that, in the lullaby orality, the phonetic musicality and rhythm have more relevance than lexical and semantic character do.
\end{abstract}

Keywords: Orality. Lullaby. Poetic Translation. Rhythm.

Recebido em: 10/08/2017

Aprovado em: 04/09/2017

Resquícios de memórias da infância nos fazem lembrar a magia dos sons e da musicalidade da canção "Frère Jacques" presentes no imaginário popular e do nosso mundo infantil, bem como, nos reporta, momentaneamente e de forma humorística, à expressão "conto do vigário" de cunho popular, cuja significação é voltada ao tema da esperteza e oportunismo religioso à época do século XVIII, cuja expressão adentrou no Brasil oriunda da

\footnotetext{
${ }^{1}$ Mestra em Estudos Literários -Universidade Federal do Pará(UFPA), Doutoranda do Programa de PósGraduação em Estudos das Tradução(DINTER). E-mail: castelobranco.rosanne@ gmail.com.
} 
cultura de Portugal e que se mantém até hoje nos discursos literários e de oralidade popular, especialmente nos povoados e nas pequenas cidades do interior do Brasil. Embora não seja o foco da atual pesquisa, abordagens de humor relatados ou musicados em poemas litúrgicos, constatamos em nossas pesquisas a presença frequente de freis e padres inseridos em linguagens poéticas orais, dentre estas "Frère Jacques", cuja canção retrata mensagens de valores morais e status, de cunho humorístico, que esse grupo eclesiástico exercia e despertava na sociedade naquele determinado período.

A investigação vai se reportar à cantiga de ninar infantil francesa "Frère Jacques", que segundo pesquisas de Sylvie Bouissou ${ }^{2}$, pesquisadora francesa e doutora em musicologia, aponta que a canção é de autoria de um dos maiores músicos franceses do século XVII a XVIII, Jean-Philippe Rameau ${ }^{3}$ (1683-1764).

A pesquisadora Sylvie Bouissou destaca ainda, que esta popular melodia tem origem em épocas distantes, mas que teve sua primeira publicação em 1811, localizada em uma relação de compositores no La Clef de Vault Corporation,fundada em 1720, tendo esta instituição recebido muitos artistas e intelectuais à época,dentre eles, Jean- Philippe Rameau. É importante considerar que a canção Frère Jacques já foi traduzida para vários idiomas no mundo linguístico e se encontra, praticamente, em todas as línguas europeias, bem como em outros continentes, com tradução para o chinês, hebraico, vietnamita, turco, japonês, indonésio, esperanto, etc.

Sabemos que o discurso canônico europeu sempre foi supremacia como referência de produção ou manifestação, excluindo qualquer tipo de produção que não estivesse de acordo com as normas estabelecidas pelos padrões canônicos europeus, como era o caso de cantigas populares e de ninar. Esses comportamentos têm origem no processo de colonização, pelo qual passam as línguas consideradas marginalizadas ou periféricas, oriundo do processo de imposição das línguas hegemônicas das línguas e literaturas europeias, interferindo e resultando numa dependência cultural.

Como ressalta Frederico Fernandes (2008, p. 01), em seu ensaio intitulado De Narrativas Orais e suas Abordagens Interdisciplinares, cuja análise se reporta à obra Oral and Written Narratives and Cultura ${ }^{4} l^{3}$, organizada por Irene Blayer e Francisco Cota Fagundes, há

\footnotetext{
${ }^{2}$ Sylvie Bouissou est agrégée de musique, docteur en musicologie (université de Paris-IV, Sorbonne) et docteur habilitée (université Paris I, Sorbonne-Panthéon Disponível em<http://www.iremus.cnrs.fr/fr/membrespermanents/sylvie-bouissou). Acesso em: 15 maio. 2016

${ }^{3}$ Disponível em: < http://www.la-croix.com/Culture/Musique/Jean-Philippe-Rameau-est-1-auteur-de-FrereJacques-2014-10-06-1216933 > Acesso em: 15 maio. 2016

${ }^{4}$ Paraliteratura:termo com que se designam todas as formas não canônicas de literatura (autoajuda,folhetins romanescos,literatura cor-de-rosa,romance ultralieght,literatura de cordel,literatura oral e tradicional,banda
} 
dois aspectos que merecem destaque no século XVI quando desponta o interesse pela coleta e estudo de textos da cultura popular, incluindo os de produção, circulação e armazenamento oral, que seriam o diletantismo, que dava ao texto poético uma aura exótica e o espírito pedagógico, de sintonia corretiva e de valoração moral. Segundo o dicionário Aurélio da Língua Portuguesa (1986), o diletante é aquele que se ocupa ou exerce uma arte por gosto, como amador, e não por ofício ou obrigação, somado ao caráter da formação pedagógica e de cunho moralizador.

Comenta Ernani Terra (apud Paes, 2014, p.16-17), de que há uma tendência em não se atribuir valor literário a esse tipo de literatura oral, geralmente considerada kitsch, e denominada também de Paraliteratura ${ }^{4}$.

No entanto, é válido registrar, que tanto a Ilíada quanto a Odisséia, poemas homéricos, circularam oralmente antes de serem compilados por escrito, tornando-se literários. Tais observações vêm ao encontro das pesquisas e idéias valorativas sobre a Poesia Oral, defendidas pelo medievalista e escritor suíço, Paul Zumthor(1915-1995), ao destacar na sua obra A letra e a voz (1993, p.35), que

A "literatura" medieval, de que se entende por "índice de oralidade" tudo o que, no interior de um texto informa-nos sobre a intervenção da voz humana em sua publicação - quer dizer, na mutação pela qual o texto passou, uma ou mais vezes, de um estado virtual à atualidade e existiu na atenção e na memória de certo número de indivíduos

E se soma à ideia de que uma forma qualquer de oralidade precede a escritura ou então é por ela intencionalmente preparada, dentro do objetivo performático (1993, p.109). Reforçando a sua análise, Zumthor acrescenta à pesquisa, de que a partir do século XIII se efetiva um aperfeiçoamento das grafias, contribuindo para um crescimento no número de textos, sobretudo dos poemas litúrgicos, em particular, de dramas eclesiásticos, e de canções de trovadores, trouvères ou Minnesänger.

É quando nos chegam cinquenta chansonniers, poesia de língua francesa, dos séculos XIII, XIV e XV. Concretamente, estudos como os de Paul Zumthor e Menéndez Vidal ${ }^{5}$ desconstruíram a ordem e modelos estabelecidos por pressupostos e regras relativas à poeticidade da linguagem medieval, possibilitando elementos inovadores aos fenômenos da oralidade poética, frente aos modelos, até então inquestionáveis quanto à retórica da escritura,

desenhada,literatura marginal e popular,etc) CEIA, Carlos. E-Dicionário de termos literários. Disponível em< http://www.edtl.com.pt.> Acesso em: 25 abr. 2016.

${ }^{5}$ Menéndez Pidal,poeta e erudito, autor de Romancero hispânico,obra que trata da história oral de um gênero poético do século XIV. 
fazendo-se repensar posições sobre as estratégias consideradas como as únicas válidas até aquele momento.

Na concepção de Zumthor (1993, p.18 e 19) existem três tipos de oralidade que correspondem a três situações de cultura. Uma primária e imediata, não comporta nenhum contato com a escritura, oriunda de grupos isolados e ausentes de sistema de simbolização gráfica ou em grupos isolados ou analfabetos. A oralidade mista, quando a influência do escrito permanece externa, parcial e atrasada, e a oralidade segunda, quando se recompõe com base na escritura num meio onde a oralidade tende a esgotar os valores da voz no uso e no imaginário.

Segundo Zumthor, entre os séculos VI e XVI, prevaleceu uma situação de oralidade mista ou segunda conforme as épocas e as regiões, as classes sociais, quando não aos indivíduos. Ao cantar ou recitar um texto improvisado ou memorizado, o poeta faz uso da sua voz e confere autoridade ao canto oral. É exatamente o prestígio da tradição unido ao que o integra nessa tradição que se dá a ação da voz que contribui para valorizá-lo e lhe conferir a permanência da sua significação no caráter performático.

\section{ORALIDADE, RITMO, TRADUÇÃO E FILOSOFIA}

Tais reflexões sobre a Oralidade Poética defendidas por Paul Zumthor nos fizeram buscar uma linha imaginária de inter-relação com o pensamento do teórico da poesia e estudioso da tradução, Henri Meschonnic (1932-2009), no que diz respeito à sua obra Poética do traduzir (2010). Independente da distinção dos referidos autores na defesa de suas temáticas, como a Oralidade e a Tradução, verificamos a importância que ambos estudiosos dão destaque à fenômenos como o sentido, o ritmo, a musicalidade, a oralidade e o aspecto cultural, assegurando a materialização desses fenômenos a fim de que se façam presentes na essência da análise das abordagens. Para encontrarmos esse ponto em comum entre ambos, observamos que Meschonnic (2010) relaciona a tradução à prática literária, através da linguagem e a teoria da linguagem na inter-relação com o sujeito e sua transformação no mundo, onde defende que cujas transformações proporcionam o ato da tradução, com apoio na oralidade subjacente. Ou seja, ritmo, musicalidade, oralidade e o sentido se fazem presentes subjetivamente e inconscientemente, provocando uma reação da mente humana frente ao processo de tradução. Meschonnic (2010: XXIV), afirma: 
Começa-se a descobrir a oralidade da literatura, não somente no teatro. [...] Descobrese que uma tradução de um texto literário deve fazer o que faz um texto literário, pela sua prosódia, seu ritmo,sua significância, como uma forma de sua individuação,como uma forma-sujeito

Meschonnic (2010) observa que o ritmo da palavra não condiz ao ritmo do sentido, bem como, sustenta que é má aquela tradução que substitui a poética do texto pela ausência de poética; ou que substitui o ritmo e a oralidade pelo descontínuo do signo; que substitui a organização de um sistema do discurso pela destruição desse sistema. O pesquisador assegura ainda, que a prática da tradução passa pela compreensão unida à interpretação na ação do próprio sujeito, não ao encontro da Identidade, mas sim, quando se concretiza na alteridade, ou seja, o indivíduo se torna capaz de se colocar no lugar do outro, mantendo uma relação de diálogo e respeito às diferenças linguísticas e culturais. Percebemos que tanto Zumthor quanto Meschonnic são contemporâneos de uma mesma geração de pensadores que interagiram e pensaram sobre o fenômeno social, temática essa que se fazia vibrante e latente com o despertar dos estudos da antropologia e da sociologia, unido ao pensamento da psicanálise, estudos dos filósofos da Escola de Frankfurt e dos pós-estruturalistas. Vale à pena ressaltar, que o pensamento moderno sobre a tradução e linguagem se constrói nas reflexões e observações de filósofos como Benjamin, Heidegger, Gadamer e Derrida (sem falar nos filósofos analíticos como Wittgenstein e Quine), onde se afirma existir uma ligação muito antiga entre o "filosofar" e o "traduzir". (Torres et all. apud Berman, 2013, p.25). Podemos constatar que as reflexões filosóficas relativas à inter-relação da linguagem, discurso e a tradução fizeram com que a tradutologia tomasse novos rumos nos seus estudos, adentrando em análises voltadas para abordagens sobre o sentido e transcendência.

Na sua análise sobre a Poética de traduzir de Meschonnic (2010), Alice Maria Ferreira $\left(1982\right.$, p.70) ${ }^{6}$ destaca a importância que as observações do linguista francês Benveniste (19021976) exerceram na academia e se somam ao pensamento de Meschonnic, na crítica à tradução ao defender a oralidade no escrito, bem como, que o ritmo está presente na linguagem, em um discurso, ou seja, seria uma configuração do discurso, e não seria uma subcategoria da forma, mas sim uma organização (disposição, configuração) de um conjunto. Alice Maria enfatiza o pensamento de Meschonnic ao comentar que, uma vez que o discurso não é separável do seu sentido, consequentemente, o ritmo é inseparável do sentido do discurso.

\footnotetext{
${ }^{6}$ FERREIRA, Alice Ma.A. Noções Fundamentais Para Se Pensar A Poética Do Traduzir de Meschonnic. Traduzires nº 1, Brasília, Maio/2012, p.94-102.
} 
Ainda na sua reflexão sobre o pensamento de Meschonnic, Alice Maria (2012, p. 100) acrescenta que o teórico combate todo e qualquer dualismo em tradução: língua de partida/língua de chegada; significante/ significado; forma/conteúdo; letra/espírito, etc. bem como, o autor critica assim a noção de signo que se opõe à noção de sujeito.

Pois o ritmo não é mais som, não é mais forma, mas um sujeito, uma historicidade. E traduzindo o discurso e não a língua, traduzimos um sujeito inscrito no seu discurso e transformado por ele, ou seja, uma historicidade. O reconhecimento do ritmo como organização do sentido pelo sujeito implica uma crítica ao signo linguístico. Pois o ritmo, sendo uma organização contínua na linguagem, evidencia a estrutura descontínua do signo. Meschonnic diz

Porque no ritmo [...] não se ouve o som, mas o assunto. Não é uma forma distinta do sentido. Traduzir, segundo o poema no discurso, é traduzir o recitativo, a narração da significância, a semântica prosódica e rítmica, não a estúpida palavra a palavra que os alvejadores veem como a procura do poético [...] (MESCHONNIC, 2010, XXXII).

O que faz lembrar na abordagem de Octavio $\mathrm{Paz}^{7}(1996)$, que teremos que considerar três realidades: o ritmo do idioma neste ou naquele lugar e em determinado momento histórico, os metros derivados do ritmo do idioma ou adaptados de outros sistemas de versificação; e o ritmo de cada poeta, sendo este último o elemento distintivo e o que separa a literatura versificada da poesia propriamente dita. Tal observação encontra ressonância nas reflexões do linguista francês, Georges Mounin (1910-1993), quando argumenta que a tradução se concretiza numa série de operações das quais o ponto de partida e o produto final não passam de significações inseridas numa respectiva cultura. Mounin relaciona o homem à sua língua e a sua inserção no mundo. O teórico defende a importância de admitirmos o fato de que a língua se modifica menos rapidamente que a experiência [do homem] no mundo (o que explica a resistência oferecida pelo léxico à estruturação), onde as transformações da experiência humana não repercutem automaticamente na língua.(1963, p. 247). Para justificar tal afirmação, Mounin nos faz relembrar de que os falantes do passado remoto buscavam suas justificativas em explicações físicas, metafísicas e religiosa para fenômenos linguísticos e que a língua conserva em estado fóssil estruturações superadas, criadas pelo homem e referentes à sua experiência do mundo no passado, resultantes em fósseis linguísticos, léxicos e sintáticos $(1963$, p. 247 e 248$)$.

Ainda na sua reflexão sobre o pensamento de Meschonnic, Alice Maria (2012, p.100) acrescenta que o teórico combate todo e qualquer dualismo em tradução: língua de

\footnotetext{
${ }^{7}$ PAZ, Octavio. Signos em Rotação.3a . Edição. São Paulo: Ed.Perspectiva,1996.
} 
partida/língua de chegada; significante/ significado; forma/conteúdo; letra/espírito, etc. bem como, o autor critica assim a noção de signo que se opõe à noção de sujeito.

Podemos constatar a inserção do pensamento heideggeriano refletida na experiência do homem frente ao processo de tradução, constantes nas teorias de Mounin e Berman quando relacionam a tradução à experiência. E “assim é a tradução: experiência. Experiência das obras e do ser-obra, das línguas e do ser-língua. Experiência, ao mesmo tempo, dela mesma, da sua essência.[...] A tradução é sujeito e objeto de um ser próprio." (BERMAN, 2013, p. 23)

Segundo Audigier (apud Mounin,1963, p. 161), a fonética está ligada à musicalidade de um texto. Mesmo tratando-se de escrita, uma história se lê em voz alta, porque de modo tradicional significa o conto de tradição oral. Ele questiona as relações entre os sons e o sentido, perguntando-se como a fonética influencia o sentido, e quais são as ligações entre sons e sentido. Segundo o estudioso, trata-se de uma associação condicionada que acaba se estabelecendo entre a imagem e a imagem visual. Na opinião de Octavio Paz (1996, p.13), ritmo, imagem e significado se apresentam simultaneamente em uma unidade indivisível e compacta: a frase poética, o verso [...] Todo ritmo verbal contém já em si mesmo a imagem e constitui, real ou potencialmente, uma frase poética completa.

\section{A CANTIGA DE NINAR E SUA TRADUÇÃO POÉTICA}

O objetivo principal desse artigo é poder identificar na cantiga de ninar francesa "Frère Jacques", os elementos de abordagens específicos trilhados pelos tradutores, que nos façam identificar as constatações de acordo com as observações de teóricos como Meschonnic, Berman e Mounin como solução para assegurar uma tradução adequada da composição musical nas línguas de chegada, do alemão e do inglês, no intuito de preservar a musicalidade, o ritmo, a performance e o sentido.

Vamos observar, a seguir, o texto francês da cantiga de ninar oral "Frère Jacques", tendo como línguas de chegada a cantiga oral alemã e a inglesa .Senão, vejamos: 
Tabela 1: Cantiga de Ninar "Frère Jacques"

\begin{tabular}{|l|l|l|}
\hline \multicolumn{1}{|c|}{ FRANCÊS } & ALEMÃO(Tradução:Prune) & $\begin{array}{l}\text { INGLÊS(Tradução:Kristina } \\
\text { Pimenova) }\end{array}$ \\
\hline $\begin{array}{l}\text { 1.Frère Jacques, Frère } \\
\text { Jacques }\end{array}$ & $\begin{array}{l}\text { 1.Bruder Jakob, Bruder } \\
\text { Jakob, }\end{array}$ & $\begin{array}{l}\text { 1.Brother John, brother } \\
\text { John }\end{array}$ \\
\hline $\begin{array}{l}\text { 2.Dormez-vous ? Dormez- } \\
\text { vous? }\end{array}$ & $\begin{array}{l}\text { 2.Schläfst du noch? Schläfst } \\
\text { du noch? }\end{array}$ & $\begin{array}{l}\text { 2.Are you sleeping? Are you } \\
\text { sleeping? }\end{array}$ \\
\hline $\begin{array}{l}\text { 3.\|Sonnez les matines ! } \\
\text { Sonnez les matines ! } \|\end{array}$ & $\begin{array}{l}\text { 3.\|: Hörst du nicht die } \\
\text { Glocken? Hörst du nicht die } \\
\text { Glocken?\| }\end{array}$ & $\begin{array}{l}\text { 3.||Morning,bells are } \\
\text { ringing? Morning,bells are } \\
\text { ringing? } \|\end{array}$ \\
\hline $\begin{array}{l}\text { 4.Din, dan, don; } \\
\text { din, dan, don }\end{array}$ & $\begin{array}{l}\text { 4.Ding dang dong, } \\
\text { ding dang dong }\end{array}$ & $\begin{array}{l}\text { 4.Ding,Ding,Dong; } \\
\text { Ding,Ding,Dong; }\end{array}$ \\
\hline
\end{tabular}

Fonte: $<$ https://www.youtube.com/watch?v=BC6rvbxdywg $>$. Acesso em: 03 abr. 2016

A tradução poética de chegada no alemão e no inglês da cantiga de ninar francesa "Frére Jacques", de Philippe Rameau, não se dá de forma literal no caráter lexical e semântico. Tal opção feita pelos tradutores se dá ao optarem por manter a sonoridade através do ritmo da canção que se traduz na musicalidade e na performance, como defende Zumthor na oralidade poética $(2013$, p.18). A referida decisão pelo ritmo em detrimento do léxico e semântico, que se traduziria no sinonímico ou tradução literal, acaba por assegurar a preservação sonora da musicalidade de forma inconsciente, tal qual a manutenção poética na transcendência junto á imaginação, conforme assinalou Berman (2013, p. 25) ao afirmar que o ato de traduzir se dá quando "a tradução é produzida pelo pensamento. Quando a tradução pode passar perfeitamente sem teoria, não sem pensamento". Ao destacar o fenômeno da voz humana, de forma subliminar e como dimensão do texto poético, determinado pelo plano físico, psíquico e sócio-cultural, constatamos inicialmente que na oralidade, a musicalidade fonética e o ritmo apresentam maior importância frente ao caráter lexical e semântico, anteriormente citado. Considerando as diferenças linguísticas e fonéticas de cada língua, observamos a opção do tradutor pela variação linguística, ou inserção de novos componentes linguísticos nas frases com o claro objetivo de manter uma aproximação ou equivalência rítmica com a sonoridade musical da cantiga de ninar infantil de origem francesa.

Senão, vejamos: 1) no primeiro verso, ao se tratar de nome próprio e que, normalmente, não se traduz de uma língua para outra, verificamos que o nome próprio Jacques em francês, recebe a tradução para Jakob em alemão, e John, em inglês. Isso deixa transparecer que houve uma busca pelo tradutor em adequar sonoramente a tradução do nome 
próprio para Jakob, o que logo nesse primeiro verso, percebemos a primeira variação linguística, uma vez que João em alemão, normalmente é traduzido por Jochen e não por Jakob. Ao mesmo tempo constatamos que a sonoridade de Jakob se adequa melhor ao contexto musical e rítmico do que Jochen, em razão da fonética do [ch] alemão ser fricativa, o que acarretaria uma mudança rítmica, motivada pela fonética.

2) No segundo verso, os verbos do inglês e do alemão se colocam em posição opostas: onde no alemão, o verbo se coloca no "no início da frase interrogativa correspondendo ao tempo verbal [schläfst] no presente e na segunda pessoa [du] acrescido de uma palavra de realce [noch], [schläfst du noch?],enquanto no francês o tempo verbal inicial é o imperativo expresso na palavra [dormez-vous?]. Ressaltemos que o pronome "du" no alemão tem caráter de proximidade de tratamento, enquanto, o inglês faz uso do presente contínuo em detrimento do presente simples [Are you slepping?]. 3)No terceiro verso, constatamos uma variação linguística bem acentuada entre o francês, o alemão e o inglês: o francês destaca que "os sinos tocam", enquanto a tradução alemã, no objetivo de preservar a harmonia das relações semânticas e musicalidade rítmica, opta por alterar o contexto linguístico ao colocar uma frase interrogativa negativa e acrescentar o verbo "hören" e o advérbio "nicht” à estrutura linguística [Hörst du nicht die Glocken?], enquanto o inglês acrescenta o advérbio "morning"(sugerindo o sentido do "amanhecer"). 4) No último verso que trata da repetição sonora de três sílabas harmônicas, também se percebe a opção da tradução da língua alemã pela manutenção das mesmas sílabas fônicas iguais à língua francesa, mantendo a mesma sonoridade, enquanto a língua inglesa opta por alterar as sílabas e, consequentemente, a sonoridade musical sofre uma pequena alteração, preservando o rítmo.

\section{CONSIDERAÇÕES FINAIS}

Ao optarmos por analisar a tradução de uma cantiga de ninar, com origem na oralidade, enveredamos por caminhos que, anteriormente, ficavam à margem dos estudos científicos como a tradução. No entanto, os novos estudos sobre a tradução poética, desenvolvidos por Meschoonic (2010), Berman (2013), Mounin (1963) e Paz (1991) nos possibilitaram reflexões e uma inter-relação com a filosofia, assegurando os novos pensamentos e reflexões na defesa do sentido e da experiência do homem no mundo, alicerçados nas abordagens filosóficas que desconstruíram ideias estruturalistas, de certa forma, pouco discutidas à época sobre a tradução e que, aos poucos, foram sendo 
reconstruídas e repensadas, frente à chegada de novos pensamentos filosóficos como os da fenomenologia, psicanálise, sociologia e antropologia.

Percebemos que é nesse intercruzamento entre filosofia, tradução e o caráter semântico de palavras que as diversas significações se colocam frente à diversidade de interpretações, onde temos que buscar o sentido do homem inserido na sua própria história e cultura através da própria linguagem e da alteridade através do outro. Com esses estudos pósestruturalistas e filosóficos constatou-se que a tradução sempre se fez presente em todas as comunidades, sejam elas as mais longínquas, e que a tradução está na essência do homem e de sua linguagem, na busca de comunicação entre os povos.

\section{REFERÊNCIAS}

ANDRADA,P.D. Resenha Meschonnic,H. Poética do traduzir.Cadernos de radução, n³3,p. 341-365, Florianópolis-jan/jun 2014/1.

BERMAN, Antoine. A tradução e a letra ou o albergue do longínquo. Tradução MarieHélene Torres, Mauri Furlan e Andreia Guerini. 2a . Ed. Tubarão/Florianópolis: Copiart/ PGET/UFSC, 2013.

FERNANDES, Frederico. De Narrativas Orais e suas Abordagens Interdisciplinares. Ipotesi, Juiz de Fora, v. 12, n. 2, p. 179 - 182, jul./dez. 2008 .

FERREIRA, Alice Maria. Noções fundamentais para se pensar a poética do traduzir de Meschonnic. Traduzires nº1, Brasília, Maio/2012,p. 94-102.

GIULIANI. Emmanuelle. Jean-Philippe Rameau est l'auteur de Frère Jacques. Disponível em: $<$ http://www.la-croix.com/Culture/Musique/Jean-Philippe-Rameau-est-l-auteur-de-FrereJacques-2014-10-06-1216933 >. Acesso em: 22 out. 2017

MESCHONNIC, H. Poética do Traduzir. Trad. Jerusa Pires Ferreira e Suely Fenerich. São Paulo, Perspectiva: 2010. 279 p.

MOUNIN, Georges. Os Problemas teóricos da tradução. Tradução de Heloysa de Lima Dantas.São Paulo: Cultrix, 1963.

PAZ, Octavio. Signos em Rotação. 3 ${ }^{\text {a }}$ Ed. São Paulo: Ed.Perspectiva,1996.

ZUMTHOR,Paul.A letra e a voz. A "literatura" medieval. Tradução: Amálio Pinheiro (Parte I) e Jerusa Pires Ferreira (Parte II). São Paulo: Companhia das Letras, 1993. 